\title{
The Challenges of Controlling Arterial Hypertension in the Elderly
}

\author{
Marcus Vinicius Bolivar Malachias ${ }^{1,2}$ \\ Faculdade de Ciências Médicas de Minas Gerais da Fundação Educacional Lucas Machado, ${ }^{1}$ Belo Horizonte, MG - Brazil \\ Instituto de Hipertensão Arterial de Minas Gerais, ${ }^{2}$ Belo Horizonte, MG - Brazil \\ Short Editorial related to the article: Hypertension Prevalence, Treatment and Control in Older Adults in a Brazilian Capital City
}

This issue of the "Archives" brings the study "Hypertension Prevalence, Treatment and Control in Older Adults in a Brazilian Capital City", by Souza ALL et al., ${ }^{1}$ disclosing data about this important cardiovascular risk factor in Goiânia, state of Goiás, Brazil, depicting the situation in our coutry. ${ }^{1}$ In this mini-editorial, we review the epidemiology of arterial hypertension $(\mathrm{AH})$ in Brazil and worldwide.

$\mathrm{AH}$ is the leading preventable cause of premature death. ${ }^{2}$ A report by the US Institute of Medicine considers $\mathrm{AH}$ as a neglected disease, because it is often overlooked by the population and underestimated by the medical community. ${ }^{3}$ Although $\mathrm{AH}$ is relatively easy to prevent, simple to diagnose and considerably less expensive to treat, it remains one of the most important causes of death. ${ }^{4}$ More than $50 \%$ of deaths from coronary artery disease and cerebrovascular accidents in the US occur in individuals with $\mathrm{AH}{ }^{5}$

A survey concluded that the estimated global prevalence of $\mathrm{AH}$ is increasing. ${ }^{6}$ Globally, $31.1 \%$ of the adult population had $\mathrm{AH}$ in 2010. The prevalence of $\mathrm{AH}$ is higher in lowand middle-income countries $(31.5 \%)$ when compared to high-income countries (28.5\%). ${ }^{6}$ From 2000 to 2010, the $\mathrm{AH}$ prevalence in high-income countries decreased by $2.6 \%$, and awareness, treatment and control substantially improved. However, in low- and middle-income countries, there was an increase in prevalence of $7.7 \%{ }^{6}$

However, a more recent analysis showed that the overall prevalence of age-standardized $\mathrm{AH}$ was $24.1 \%$ in men and $20.1 \%$ in women by $2015 .^{7}$ The worldwide number of adults with $\mathrm{AH}$ increased from 594 million in 1975 to 1.13 billion in 2015 , increasing mainly in low- and middle-income countries. ${ }^{7}$

In relation to the elderly population, the International Mobility In Aging Study (IMIAS) showed that the prevalence of $\mathrm{AH}$ ranged from $53.4 \%$ to $83.5 \%$ in five assessed cities: Kingston (Canada), Saint-Hyacinthe (Canada), Tirana (Albania), Manizales (Colombia) and Natal (Brazil). ${ }^{8}$ More than 2/3 of the hypertensive participants were aware of the diagnosis (of $67.3 \%$ in Saint-Hyacinthe to $85.4 \%$ in Tirana), especially among women. ${ }^{8}$ Although more than $80 \%$ of the patients were receiving treatment, the control rates were low: $37.6 \%$

\section{Keywords}

Hypertension/epidemiology; Aged; Hypertension/ prevention and control; Prevalence; Arterial Pressure.

\section{Mailing Address: Marcus Vinicius Bolivar Malachias •}

Instituto de Hipertensão Arterial de Minas Gerais - Av. Do Contorno, 3915,

Bairro São Lucas. Postal Code 30110-021, Belo Horizonte, MG - Brazil

E-mail: mbolivar@cardiol.br

DOI: $10.5935 / a b c .20190020$ in Manizales; 29.5\% in Kingston; 26.5\% in Saint-Hyacinthe; $24 \%$ in Tirana and $22 \%$ in Natal, with the Brazilian city showing the least effective disease control. ${ }^{8}$

Currently, Canada has the world's best rates of AH control, estimated at $68 \%$ of the affected population. ${ }^{9}$ That country has achieved a dramatic reduction regarding the lack of diagnosis knowledge (43\% in 1991 versus 17\% in 2013), with the percentage of patients being treated increasing from $34 \%$ to $80 \%$ in the same period. ${ }^{9}$

The US has shown better $\mathrm{AH}$ control in women than in men (55.3\% versus $38.0 \%$ in 2009-2012); as well as among Whites compared to Blacks and Hispanics (41.3\% versus $31.1 \%$ and $23.6 \%) .{ }^{10}$ In that country, there is a better $\mathrm{AH}$ control among the elderly than in young individuals $(50.5 \%$, in adults aged 60 to 70 years, versus $34.4 \%$ in patients aged 18 to 39 years in 2011-2012). ${ }^{11,12}$ As for the population aged 75 years or older, there was a slight decline in control $(46 \%)$, which continues to decline from 80 years onward $(39.8 \%){ }^{12}$

In Brazil, data from the "Surveillance System for Risk and Protective Factors for Chronic Diseases by Telephone Survey (Vigitel)" (2006 to 2014), indicate that self-reported AH in adults living in capitals ranged from $23 \%$ to $25 \% .{ }^{13,14}$ Among adults aged 60 to 64 years, the prevalence was $44.4 \%$; in those aged 65 to 74 years, $52.7 \%$; and from 75 years onward, 55\%. ${ }^{13}$ The rates of knowledge ( $22 \%$ to $77 \%)$, treatment $(11.4 \%$ to $77.5 \%$ ) and control (10.1\% to $35.5 \%$ ) varied widely, depending on the assessed population. ${ }^{15}$ Data from VIGITEL 2017, related to 2016 , showed that $60.9 \%$ of adults aged 65 years and older reported the diagnosis of $\mathrm{AH}$ in a telephone survey. ${ }^{16}$

The first Brazilian Registry of $\mathrm{AH}$ reveals encouraging data, demonstrating a significant improvement in $\mathrm{AH}$ control in the country, when considering the population treated in referral centers. ${ }^{17}$ Based on the population treated in 45 centers distributed throughout all Brazilian regions, with a mean age of 61 years, blood pressure (BP) control was observed below $140 / 90 \mathrm{mmHg}$ in $59.6 \%$ of the patients, considering the stabilization of BP in all visits, and $60.6 \%$ when considering the measurements in the one-year follow-up consultation. ${ }^{17}$ Such rates, however, do not reflect the overall situation of $\mathrm{AH}$ control in the country.

In the article by Souza ALL et al.,1 published in this issue, the total prevalence of $\mathrm{AH}$ in the assessed elderly was $74.9 \%$, being higher among men (78.6\%). The treatment rate was $72.6 \%$ and the percentage of $\mathrm{AH}$ control was $50.8 \%$, being higher among women. ${ }^{1}$ These data show that, although there is still need for improvement, there has been an important increase in the rates of diagnosis, knowledge, treatment and control of $\mathrm{AH}$ in our country, especially among the elderly population. 


\section{References}

1. Sousa ALL, Batista SR, Sousa AS, Pacheco JAS, Vitorino Pv, Pagotto V. Prevalência, tratamento e controle da hipertensão arterial em idosos de uma capital brasileira. Arq Bras Cardiol. 2019; 112(3):271-278.

2. Lim SS, Vos T, Flaxman AD,Danali G, Shibuya K, Adair-Rohani H, et al., A comparative risk assessment of burden of disease and injury attributable to 67 risk factors and risk factor clusters in 21 regions, 1990-2010: a systematic analysis for the Global Burden of Disease Study 2010. Lancet. 2012;380(9859):2224-60.

3. Institute of Medicine (US) Committee on Public Health Priorities to Reduce and Control Hypertension. A Population-Based Policy and Systems Change Approach to Prevent and Control Hypertension. Washington (DC): National Academies Press (US); 2010.

4. Mitka M. IOM urges more attention by physicians, public on "neglected" hypertension. JAMA. 2010;303(14):1354-5.

5. Ford ES. Trends in mortality from all causes and cardiovascular disease among hypertensive and nonhypertensive adults in the United States. Circulation. $2011 ; 123(16): 1737-44$.

6. Mills KT, Bundy JD, Kelly TN, Reed JE, Kearney PM, Reynolds K, et al. Global disparities of hypertension prevalence and control: a systematic analysis of population-based studies from 90 countries. Circulation. 2016; 134(6):441-50

7. NCD Risk Factor Collaboration (NCD-RisC). Worldwide trends in blood pressure from 1975 to 2015: a pooled analysis of 1479 population-based measurement studies with 19.1 million participants. Lancet. 2017; 389(10064):37-55.

8. Doulougou B, Gomez F, Alvarado B, Guerra RO, Ylli A, Guralnik J, et al. Factors associated with hypertension prevalence, awareness, treatment and control among participants in the International Mobility in Aging Study (IMIAS). J Hum Hypertens. 2016;30(2):112-9.

9. Schiffrin EL, Campbell NR, Feldman RD, Kaczorowski J, Lewanczuck R, Padwal R, et al. Hypertension in Canada: past, present, and future. Ann Glob Health. 2016; 82(2):288-99.
10. National Center for Health Statistics (U.S.). Health, United States, 2013: With Special Feature on Prescription Drugs. Hyattsville, MD: National Center for Health Statistics (US); 2014.

11. Nwankwo T, Yoon SS, Burt V, Gu Q. Hypertension among adults in the United States: National Health and Nutrition Examination Survey, 2011-2012. NCHS Data Brief. 2013 Oct (133):1-8.

12. Bromfield SG, Bowling CB, Tanner RM, Peralta CA, Odden MC, Oparil $\mathrm{S}$, et al. Trends in hypertension prevalence, awareness, treatment, and control among US adults 80 years and older, 1988-2010. J Clin Hypertens (Greenwich). 2014; 16(4):270-6.

13. VIGITEL Brasil 2014. Vigilância de fatores de risco e proteção para doenças crônicas por inquérito telefônico. [Internet]. Disponível em: http:// portalsaude.saude.gov.br/images/pdf/2015/abril/15/PPT-Vigitel-2014-. pdf . Acesso em: 21/12/2018.

14. Malachias M, PlavnikFL, MachadoCA, Malta D, Scala LCN, FuchsS. 7th Brazilian Guideline of Arterial Hypertension: Chapter 1 - Concept, Epidemiology and Primary Prevention. Arq Bras Cardiol. 2016; 107(3 Suppl 3):1-6.

15. Scala LC, Magalhães LB, Machado A. Epidemiologia da hipertensão arterial sistêmica. In: Moreira SM, Paola AV; Sociedade Brasileira de Cardiologia. Livro Texto da Sociedade Brasileira de Cardiologia. 2ạ. ed. São Paulo: Manole; 2015. p. 780-5.

16. Brasil. Ministério da Saúde (MS). Secretaria de Vigilância em Saúde. Departamento de Vigilância de Doenças e Agravos não Transmissíveis e Promoção da Saúde. VIGITEL Brazil 2017: surveillance of risk and protective factors for chronic diseases by telephone survey: estimates of Frequency and sociodemographic distribution of risk and protective factors for chronic diseases in the capitals of the 26 Brazilian states and the Federal District in 2017 - Brasília; 2018.[Citado em 218 out 12) Disponível em http://bvsms. saude.gov.br/bvs/publicacoes/vigitel_brasil_2017_vigilancia_fatores_risco. pdf. Acesso em 21/12/2018.

17. Lopes RD, Barroso WKS, Brandão AA, Barbosa EC, Malachias MVB, Gomes MM, et al. First Brazilian Registry of Hypertension. Am Heart J. 2018 Nov 205:154-7. 